\title{
Collaborative Behavior and Supporting Technologies
}

\author{
Jonathan Grudin ${ }^{1}$ and Steven Poltrock ${ }^{2}$ \\ ${ }^{1}$ Microsoft Research, Redmond, Washington, USA \\ ${ }^{2}$ Boeing Phantom Works, Seattle, Washington, USA \\ jgrudin@microsoft.com, steven.poltrock@boeing.com
}

\begin{abstract}
Collaboration technologies are emerging rapidly to support groups, organizations, and society. This half-day course includes lectures, video illustrations, and case studies that cover experiences, current possibilities, and future trends, focusing on areas of rapid change. How might organizations use weblogs? Why has digital video taken so long to take hold, and what is happening now? What is the promise and practice with workflow management?
\end{abstract}

Keywords: collaboration technology, CSCW, adoption, emerging technologies.

\section{Collaboration Technologies}

In this half-day tutorial we focus on behavioral aspects affecting successful technology adoption, focusing on emerging and rapidly evolving collaboration technologies. We survey the current state of research and application, and identify specific trends and general issues that are central to design and use. Most INTERACT participants are aware of Computer Supported Cooperative Work research and collaboration technology, but the area is growing rapidly, with fundamental contributions coming from many directions.

\section{Design and Evaluation Challenges}

Successfully overcoming technical hurdles does not guarantee success. We briefly review behavioral, social, and organizational phenomena that undermine technically impressive applications, and some methods to address the challenges.

\section{Research and Application}

Our survey is structured around collaboration activities, which in turn are structured by human organizational entities such as teams, projects, companies, and communities. In this tutorial we focus on collaboration requirements addressed by technologies to support teams or groups, organizations, and communities.

\subsection{Supporting Groups}

Support for small groups and teams became a major focus of research and development when local area networks became widespread. Research into group 
behavior has identified a range of group modes, functions, and task types, each presenting opportunities and challenges for technology support.

\subsection{Supporting Organizations}

In organizations, asynchronous sharing of work objects and coordination (workflow management) are key issues. Building on progress in group support, significant advances in enterprise-wide technology use are appearing.

\subsection{Supporting Communities}

Social spaces and interaction technologies appear (and disappear) with remarkable rapidity and force. Even ephemeral use often serves purposes and provides lessons.

\section{The Future of Digitally Mediated Interaction}

Our conviction is that the pace of technology impact is picking up. New technologies have complex effects that can be liberating and constraining, and that facilitate intended and unintended sharing of information. We note the potential of these technologies, and decisions that we must make as individuals and as members of organizations and society as to how they will be used.

\section{Further Reading}

Poltrock, S.E., Grudin, J.: Videoconferencing: Recent experiences and reassessment. In: Proc. HICSS 2005, IEEE Digital Library, Los Alamitos (2005)

Grudin, J.: Enterprise knowledge management and emerging technologies. In: Proc. HICSS 2006, IEEE Digital Library, Los Alamitos (2006)

Efimova, L., Grudin, J.: Crossing boundaries: A case study of employee blogging. In: Proc. HICSS 2006, IEEE Digital Library, Los Alamitos (2007)

Poltrock, S.E.: unpublished manuscript. Workflow in knowledge work: The promises and the perils. 